\title{
Quantification of Flavonoids in Brazilian Orange Peels and Industrial Orange Juice Processing Wastes
}

\author{
Regina M. S. Pereira1, Begoña Giménez-Cassina López², Susana N. Diniz1, \\ Alyne Alexandrino Antunes ${ }^{3}$, Daniel Moreno Garcia4, Carlos Rocha Oliveira5, \\ Maria Cristina Marcucci ${ }^{*}$
}

\begin{abstract}
${ }^{1}$ Post-Graduated School in Pharmacy and Biotechnology, Anhanguera University of São Paulo-UNIAN-SP, São Paulo, Brazil ${ }^{2}$ Department of Plant Biology and Pharmacy Course, Institute of Biology, University of Campinas, UNICAMP, Campinas, Brazil ${ }^{3}$ Centro Interdisciplinar de Investigação Bioquímica, Universidade de Mogi das Cruzes-UMC, Mogi das Cruzes, Brazil ${ }^{4}$ Departamento de Farmacologia, Escola Paulista de Medicina, Universidade Federal de São Paulo, São Paulo, Brazil ${ }^{5}$ Escola de Ciências da Saúde, Universidade Anhembi Morumbi, São Paulo, Brazil Email: *cris.marcucci@yahoo.com.br
\end{abstract}

How to cite this paper: Pereira, R.M.S. López, B.G.-C., Diniz, S.N., Antunes, A.A., Garcia, D.M., Oliveira, C.R. and Marcucci, M.C. (2017) Quantification of Flavonoids in Brazilian Orange Peels and Industrial Orange Juice Processing Wastes. Agricultural Sciences, 8, 631-644.

https://doi.org/10.4236/as.2017.87048

Received: March 15, 2017

Accepted: July 24, 2017

Published: July 27, 2017

Copyright (c) 2017 by authors and Scientific Research Publishing Inc. This work is licensed under the Creative Commons Attribution International License (CC BY 4.0)

http://creativecommons.org/licenses/by/4.0/

(c) (†) Open Access

\begin{abstract}
The flavonoid content in orange peels of different Brazilian citrus varieties such as bahia, lima, lima-of-persian, morcote, pera, ponkan, seleta, cravo, kinkan and pomelo was assessed. Industry processing juice wastes such as bagasse, bagasse residues, animal feeding bagasse, pulp WEUE and CORE-wash were also analyzed. The HPLC analysis indicates that the most abundant flavonoids found in these Brazilian citrus peels are hesperidin and naringin. The solvents used are selective for flavonoid extraction, and depending on their polarity, glycoside or aglycone flavonoids are extracted. The use of multivariate analysis shows that DMSO is the best solvent to extract glycosides flavanones while hexane displays high selectivity in the extraction of polymethoxylated flavones. The flavonoids present in the orange wastes, obtained at different stages of the industrial processing, are qualitative and quantitatively different. The identification and quantification of the flavonoid composition in each Brazilian citrus variety were evaluated and allowed the selection of the best solvent for the extraction of each specific class of flavonoids. These compounds were found to be more abundant in the fruit peels than in their juices, revealing their great industrial potential. The residual portion of the processing juices is also rich in flavonoids, depending on the processing step.
\end{abstract}

\section{Keywords}

Citrus, Orange Peel, Flavonoid, Brazilian Orange, Orange Juice Processing Wastes 


\section{Introduction}

Flavonoids in citrus are a major class of secondary metabolites that have significant impact in human life [1]-[6]. These compounds are present in many sources, including citrus fruits [7] [8] [9] [10] [11]. The therapeutic or even toxic activity, e.g., antioxidant, anti-inflammatory, antibacterial, antimutagenic, antiviral and antimetastatic effects, has been reported in a great number of these flavonoids [12] [13] [14] [15]. Hesperidin, the most abundant flavonoid in Citrus aurantium, influences vascular permeability [16] [17]; naringin and hesperetin inhibit the in vitro proliferation of human breast cancer cells [6] [8] [18]; tangeretin and nobiletin are the most active antimutagen flavonoids tested so far, and many display chemopreventive potential [19] [20] [21]. The pharmacological potential of these polyphenolic compounds is the reason why the interest of the pharmaceutical industry on these compounds has increased over the last years [14] [22].

Therefore, the analysis of citrus flavonoids has become essential. There are several studies published on the HPLC analysis of citrus flavonoids [8] [23] [24] [25]. However, there are few reports on the HPLC analysis of citrus Brazilian fruit peels [10] [26].

In Brazil, there are many different species and varieties of citrus. The most common are: lima orange, lima-of-persian, seleta, morcote, mexerica poncan, bahia and pera.

The purpose of this paper is to assess different methods for the extraction of the flavanones: hesperidin, hesperetin, naringin, naringenin and the polymathoxylated flavone tangeretin, in ten different Brazilian citrus. The compounds were identified by comparison with standards and quantified by HPLC analysis. Furthermore, these results were analyzed using multivariate analysis, allowing the identification of the best extraction method. We also analyzed and quantified flavonoids in industrial juice processing waste named "bagacilio" (BCGD), bagasse (BCD), animal feeding bagasse (BRD), pulp WEUE (PUD) and COREwash (CRD).

\section{Materials and Methods}

\subsection{Chemicals and Reagents}

The standards used in the identification and quantification of the peaks in orange peels by HPLC were purchased from Sigma (USA) (quercetin, hesperidin, hesperetin, naringin and naringenin) and tangeretin from Chromadex (USA). Solvents such as DMSO (dimethylsulfoxide) were purchased from Ecibra (Brazil), hexane from Synth (Brazil) and methanol from Merck (Germany).

\subsection{Oranges}

Ten different types of citrus were analyzed, bahia (Citrus sinensis L.Osbeck var. baía), lima (Citrus aurantifolia or Citrus limetta-Rutaceae), lima-of-persian (Citrus limettioides), morcote (Citrus aurantium $\times$ reticulata var. murcote), pera 
(Citrus sinensis L. Osbeck), ponkan (Citrus reticulata Blanco var. poncan), seleta (Citrus sinensis L. Osbeck var. seleta), cravo (Citrus reticulata Blanco), kinkan (Fortunella margarita) and pomelo (Citrus paradisi Macfayden), and purchased at local markets in São Paulo, Brazil.

\subsection{Sample Preparation}

The orange peels were further grounded to a fine powder using a blender (Arno, Brazil) and dried at $70^{\circ} \mathrm{C}$ using drying oven (Fanem ${ }^{\text {tx }}$, Brazil). This fine powder (60 mesh, $0.25 \mathrm{~mm}$ ) was extracted for 24 hours in $500 \mathrm{mg}$ portions with $10 \mathrm{~mL}$ of DMSO, hexane, methanol or DMSO after hexane extraction. This last portion, after extracting with hexane, filtering and drying, was re-extracted with DMSO (500 mg with $10 \mathrm{~mL}$ of DMSO). The extracts were filtered using a $0.45 \mu \mathrm{m}$ filter (minisart, Sartorius, Germany) and analyzed by HPLC in triplicate. Samples of orange peel residues were dried at $70^{\circ} \mathrm{C}$ and processed using the same procedure as the orange peels.

\subsection{Chromatographic Analysis}

Orange samples were analyzed by HPLC in a D-7000 Merck-Hitachi equipment (Merck-Hitachi, Darmstadt, Germany) with a L-7100 pump and a L-7200 autosampler. The chromatographic conditions were: reverse phase column (Lichrochart $100 \mathrm{RP}-18 ; 12.5 \times 0.4 \mathrm{~cm}$, diameter of particle of $5 \mu \mathrm{m}$, Merck, Darmstadt, Germany) and oven temperature of $35^{\circ} \mathrm{C}$. The mobile phase was water-formic acid (5\% (v/v) of formic acid, solvent A) and methanol (solvent B), with a flow of $1 \mathrm{~mL} \cdot \mathrm{min}^{-1}$, using a linear gradient (starting with $30 \%$ of solvent $\mathrm{B}$, increasing to $80 \%$ in 20 minutes and going back to $30 \%$ of solvent B in 22 minutes remaining in this conditions until 25 minutes). The time of the analysis was 25 minutes and the detection was performed using a diode array detector (HPLC-DAD) (Merck-Hitachi, L-7450) and the wavelengths used were $280 \mathrm{~nm}$ and $340 \mathrm{~nm}$. The software used for data analysis was the Chromatography Dates Station DAD Manager).

\subsection{Statistical Analysis}

In the research for possible differences between the groups, analysis of variance (ANOVA) followed by Tukey-Kramer multiple comparison test (parametric data) and Kruskal-wallis (nonparametric data) was used. When the comparison was only between two groups Student unpaired $t$ test was used. $\mathrm{P}<0.05$ was considered statistically significant (GraphPad, Prism 6.0, San Diego, CA, USA).

\subsection{Multivariate Statistical Analysis}

Principal component analysis (PCA) is an analysis that allows to describe the variation (or dispersion) of one determined data set. Samples (orange peels) were represented by a row vector while the variables (different extracting solvents) were represented by a column vector. This matrix can be decomposed in two different matrices, the scores that represent the position of a sample in this 
new system of cartesian coordinates and the loadings that represents the weight of each variable in this new axles of coordinates. In the present work, the analysis of the composition of the orange peels and the industry processing wastes was assessed using The Unscrambler 10.2 software (CAMO, USA). PCA and Hierarchical Clustering Analysis (HCA) using Ward's method on previously normalized data, were performed.

\section{Results and Discussion}

\subsection{Extraction of Flavonoids in Orange Peels}

Orange peels are a good source of flavonoids such as glycosides and polymethoxylated flavones [11]. Orange peel extracts of different citrus varieties were prepared in methanol, hexane and DMSO. The flavonoid content in the orange peels was quantified using external standards such as quercetin, hesperidin, hesperetin, naringin, naringenin and tangeretin (Figure 1).

Typical chromatograms of the extracts are shown in Figure 2. The most abundant flavonoid extracted by DMSO and methanol, in all orange peels studies, was hesperidin (Table 1).

More polar solvents like methanol or DMSO display better extraction efficiency of glycoside flavanones such as naringin, hesperidin and naringenin. Quercetin (aglycone flavonol) was identified in some orange peels extracted with these same solvents. Quercetin was identified in peels of Navel variety citrus [27]. However, hexane is the solvent of choice to extract polymethoxylated flavones, such as tangeretin. Nobiletin, which is also a polymethoxylated flavone,

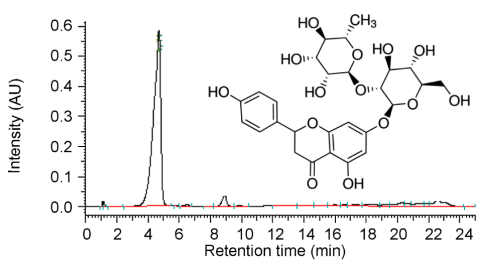

Naringin (flavanone glycoside) $(\mathrm{Rt}=4.71 \mathrm{~min})$

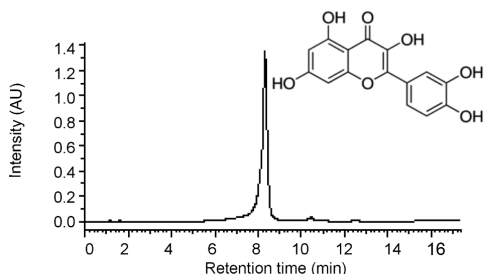

Quercetin (flavonol aglycone) $(\mathrm{Rt}=8.33 \mathrm{~min})$

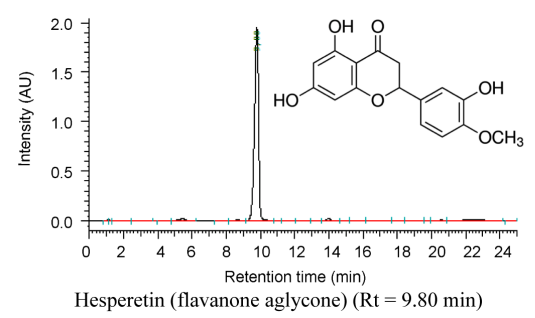

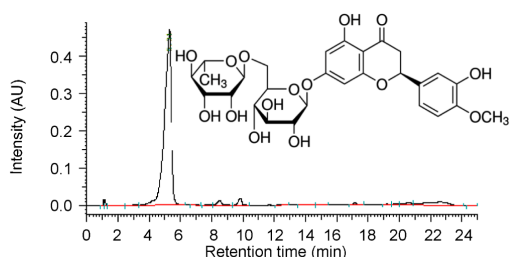

Hesperidin (flavanone glycoside) $(\mathrm{Rt}=5.31 \mathrm{~min})$

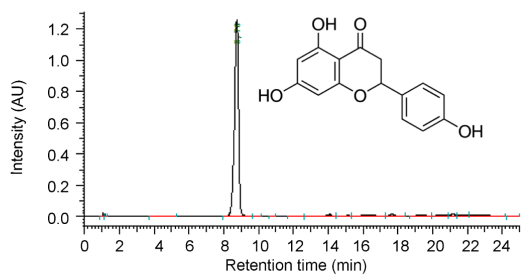

Naringenin (flavanone aglycone) $(\mathrm{Rt}=8.76 \mathrm{~min})$

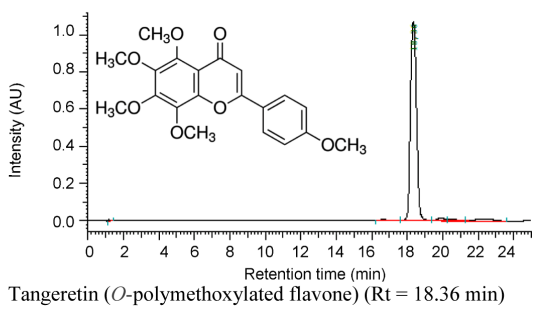

Figure 1. Chromatogram of standards with respective retention time (Rt, in minutes) and chemical structures. 
was identified in the extracts by comparison with the UV-Vis spectra library, but it was not quantified (Figure 2).

\subsection{Effect of the Extracting Solvents on the Orange Peels Composition}

The multivariate analysis, showed a selective extraction of flavonoids using different solvents. The extractions of the orange peels were named in accordance with the solvent used in the extraction and type of orange (Table 1).
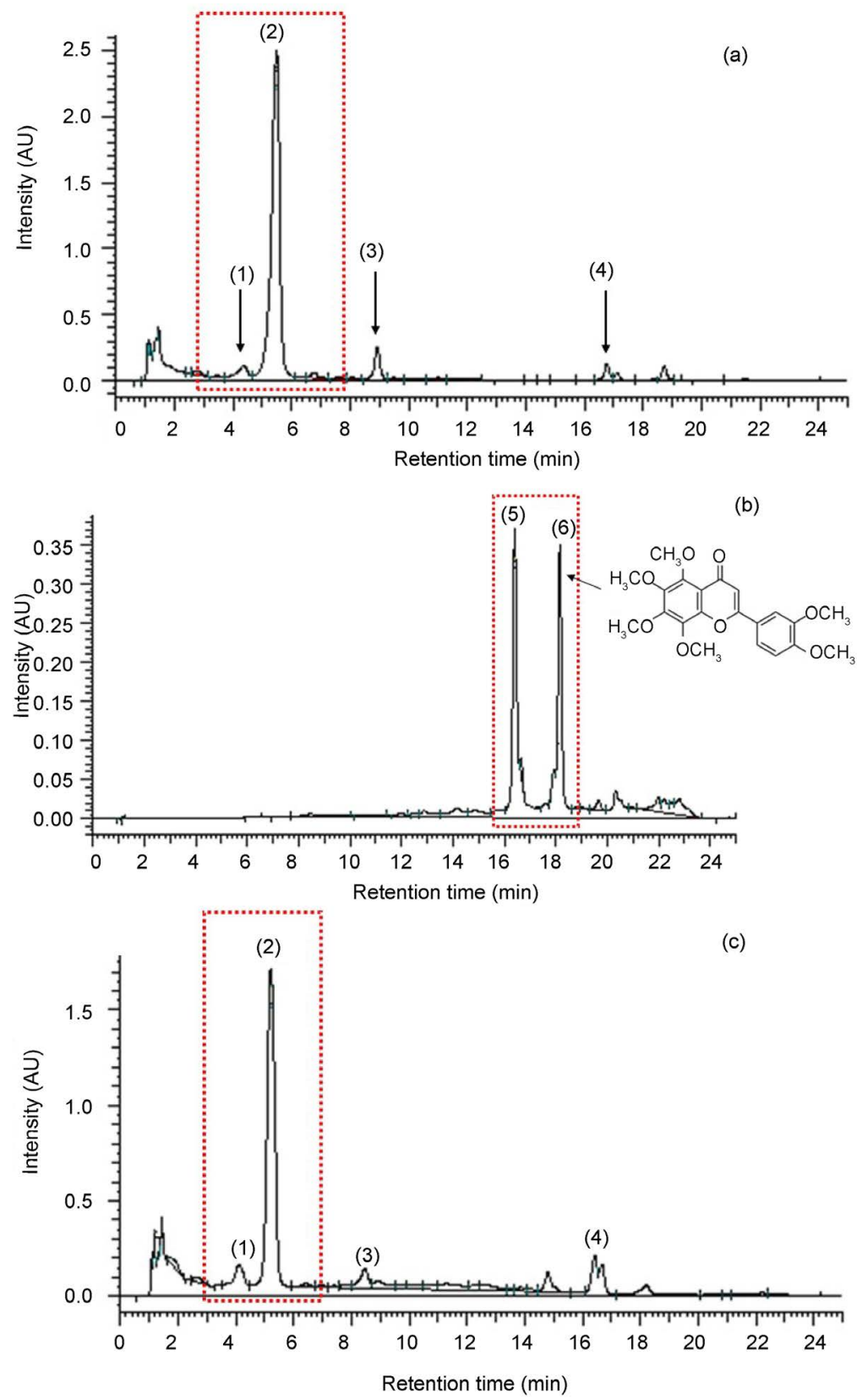

Figure 2. Typical HPLC-DAD chromatogram of baia orange peels extracted with DMSO (a), hexane (b) and methanol (c). Peak 1 is naringin, 2 is hesperidin, 3 is narigenin, 4 is tangeretin, 5 is tangeretin and 6 nobiletin (chemical structure showed in (b)), identified by comparison with the UV-Vis spectrum of the spectrum library, not quantified). 
Table 1. Flavonoids in orange peels (expressed in mg of each flavonoid per gram of dried peel $)^{*}$.

\begin{tabular}{|c|c|c|c|c|c|c|}
\hline \multirow[t]{2}{*}{ Orange } & \multirow[t]{2}{*}{ Abbrev.* } & \multicolumn{5}{|c|}{ Flavonoid** } \\
\hline & & Naringin & Hesperidin & Hesperetin & Naringenin & Tangeretin \\
\hline \multicolumn{7}{|l|}{$\begin{array}{c}\text { DMSO } \\
\text { extraction }\end{array}$} \\
\hline Baia & LBD & $2.06 \pm 1.78$ & $41.17 \pm 0.08$ & $0.00 \pm 0.00$ & $1.78 \pm 0.01$ & $1.02 \pm 0.00^{S}$ \\
\hline Lima & LLD & $0.80 \pm 0.02^{\mathrm{A}}$ & $28.30 \pm 0.02$ & $0.00 \pm 0.00$ & $0.85 \pm 0.01^{\mathrm{L}}$ & $0.84 \pm 0.01$ \\
\hline Lima-of-persian & LIPD & $1.73 \pm 0.05$ & $0.00 \pm 0.00$ & $0.00 \pm 0.00$ & $0.00 \pm 0.00$ & $0.19 \pm 0.03^{\mathrm{YZ}}$ \\
\hline Morcote & MOD & $0.88 \pm 0.14^{\mathrm{A}}$ & $2.10 \pm 0.29$ & $0.00 \pm 0.00$ & $0.47 \pm 0.81^{\mathrm{LM}}$ & $1.59 \pm 0.03^{\mathrm{b}}$ \\
\hline Morcote (dried) & MSD & $0.96 \pm 0.01^{\mathrm{A}}$ & $2.27 \pm 0.02^{\mathrm{H}}$ & $0.00 \pm 0.00$ & $1.80 \pm 0.01$ & $4.44 \pm 0.01$ \\
\hline Pera & LPD & $0.00 \pm 0.00$ & $8.61 \pm 0.03$ & $0.00 \pm 0.00$ & $0.00 \pm 0.00$ & $1.22 \pm 0.02^{\mathrm{W}}$ \\
\hline Ponkan & PKD & $1.37 \pm 0.03^{\mathrm{A}}$ & $33.49 \pm 0.16$ & $0.00 \pm 0.00$ & $\begin{array}{c}0.86 \pm \\
0.01^{\text {LMNP }}\end{array}$ & $2.55 \pm 0.01$ \\
\hline Seleta & SLD & $0.79 \pm 0.01^{\mathrm{A}}$ & $39.39 \pm 0.12$ & $0.00 \pm 0.00$ & $2.07 \pm 0.01^{\mathrm{KOQ}}$ & $0.80 \pm 0.01^{\mathrm{Vc}}$ \\
\hline \multicolumn{7}{|l|}{$\begin{array}{c}\text { Hexane } \\
\text { extraction }\end{array}$} \\
\hline Baia & $\mathrm{LBH}$ & $0.00 \pm 0.00$ & $0.00 \pm 0.00$ & $0.00 \pm 0.00$ & $0.00 \pm 0.00$ & $0.53 \pm 0.01$ \\
\hline Lima & LLH & $0.00 \pm 0.00$ & $0.00 \pm 0.00$ & $0.00 \pm 0.00$ & $0.00 \pm 0.00$ & $0.06 \pm 0.00$ \\
\hline Lima-of-persian & LIPH & $0.00 \pm 0.00$ & $0.00 \pm 0.00$ & $0.00 \pm 0.00$ & $0.00 \pm 0.00$ & $0.25 \pm 0.01^{\mathrm{Y}}$ \\
\hline Morcote & $\mathrm{MOH}$ & $0.00 \pm 0.00$ & $0.00 \pm 0.00$ & $0.00 \pm 0.00$ & $0.00 \pm 0.00$ & $1.67 \pm 0.02$ \\
\hline Morcote (dried) & MSH & $0.00 \pm 0.00$ & $0.00 \pm 0.00$ & $0.00 \pm 0.00$ & $0.00 \pm 0.00$ & $2.42 \pm 0.07$ \\
\hline Pera & PLH & $0.00 \pm 0.00$ & $0.00 \pm 0.00$ & $0.00 \pm 0.00$ & $0.00 \pm 0.00$ & $0.50 \pm 0.01^{\mathrm{TU}}$ \\
\hline Ponkan & $\mathrm{PKH}$ & $0.00 \pm 0.00$ & $0.00 \pm 0.00$ & $0.00 \pm 0.00$ & $0.00 \pm 0.00$ & $2.85 \pm 0.01$ \\
\hline Seleta & $\mathrm{SLH}$ & $0.00 \pm 0.00$ & $0.00 \pm 0.00$ & $0.00 \pm 0.00$ & $0.00 \pm 0.00$ & $0.39 \pm 0.00$ \\
\hline \multicolumn{7}{|l|}{$\begin{array}{l}\text { Methanol } \\
\text { extraction }\end{array}$} \\
\hline Baia & LBM & $2.98 \pm 0.02$ & $37.84 \pm 0.13$ & $0.86 \pm 0.01$ & $4.74 \pm 0.01$ & $1.09 \pm 0.02$ \\
\hline Lima & LLM & $0.00 \pm 0.00$ & $24.93 \pm 0.13$ & $0.00 \pm 0.00$ & $0.82 \pm 0.01$ & $0.44 \pm 0.01$ \\
\hline Lima-of-persian & LIPM & $0.00 \pm 0.00$ & $3.30 \pm 0.01$ & $1.21 \pm 0.01^{\mathrm{I}}$ & $0.00 \pm 0.01$ & $0.17 \pm 0.02$ \\
\hline Morcote & MOM & $1.64 \pm 0.01$ & $3.60 \pm 0.11^{\mathrm{G}}$ & $0.00 \pm 0.00$ & $0.00 \pm 0.00$ & $2.97 \pm 0.09$ \\
\hline Morcote (dried) & MSM & $2.23 \pm 0.06$ & $4.69 \pm 0.01$ & $0.00 \pm 0.00$ & $4.73 \pm 0.06^{\mathrm{J}}$ & $3.79 \pm 0.01$ \\
\hline Pera & LPM & $0.00 \pm 0.00$ & $10.66 \pm 0.09$ & $0.00 \pm 0.00$ & $0.00 \pm 0.00$ & $1.17 \pm 0.02^{\mathrm{S}}$ \\
\hline Ponkan & PKM & $0.47 \pm 0.01^{\mathrm{ABC}}$ & $29.10 \pm 0.04^{\mathrm{F}}$ & $0.00 \pm 0.00$ & $0.75 \pm 0.01^{\mathrm{LMN}}$ & $0.84 \pm 0.01^{\mathrm{V}}$ \\
\hline Seleta & SLM & $2.12 \pm 0.04^{\mathrm{E}}$ & $36.36 \pm 0.02$ & $0.00 \pm 0.00$ & $1.96 \pm 0.02^{\mathrm{KO}}$ & $0.19 \pm 0.03^{\mathrm{YZa}}$ \\
\hline
\end{tabular}

${ }^{*}$ Abbreviation used in multivariate analysis; ${ }^{*}$ Results in triplicates $( \pm \mathrm{SD})$. Detection limit of $0.3 \mathrm{ppm}$ or $0.003 \mathrm{mg} / \mathrm{g}$. Data are means \pm S.D. of three independent determinations. Means within a column of Naringin sharing the letter $\mathrm{A}$ are significantly reduced $(\mathrm{p}<0.05)$ by One-Way ANOVA compared to LBM, B compared to LBD, C compared to MSM, E is significantly increased by One-Way ANOVA compared to PKM. Means within a column of Hesperidin sharing the letter $\mathrm{F}$ are not significantly different $(\mathrm{p}>0.05)$ by One-Way ANOVA compared to LLD, G compared to LIPM and H compared to MOD. Means within a column of Hesperetin sharing the letter I are significantly increased $(p<0.05)$ by Student unpaired t-test comparing LBM to LIPM. Means within a column of Naringenin sharing the letter J are not significantly different ( $p>0.05$ ) by One-Way ANOVA compared to LBM, L compared to LLM, M compared to LLD, N compared to MOD and P compared to PKM. Means within a column of Tangeretin sharing the letter S are not significantly different $(\mathrm{p}>0.05$ ) by One-Way ANOVA compared to LBM, T compared to LBH, U compared to LLM, V compared to LLD, W compared to LPM, Y compared to LIPM, Z compared to LIPH, a compared to LIPD, b compared to MOH and c compared to PKM. 
In the PCA of Figure 3 it is possible to observe the separation of the extracts in three groups according to their chemical composition and extracting solvent. PC1 and PC2 can explain 97\% of the data variance, and the accumulated variance of PC3 is 99\%. The hexane extracts are clustered together while there is no clear separation between the methanol and DMSO extracts. The loadings plot show that tangeretin is responsible for gathering all the hexane extracts together

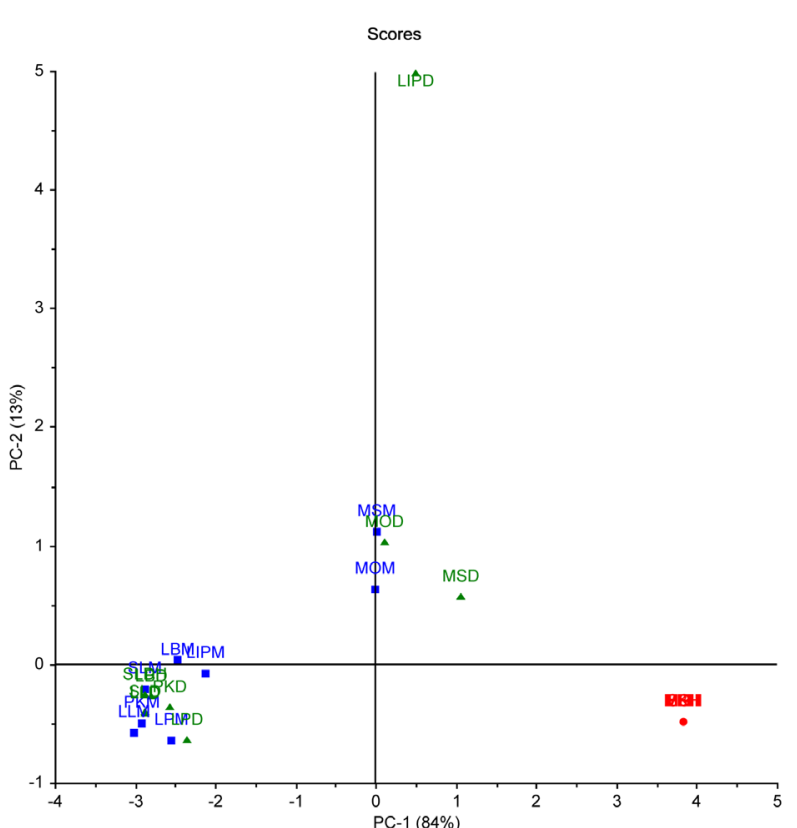

(a)

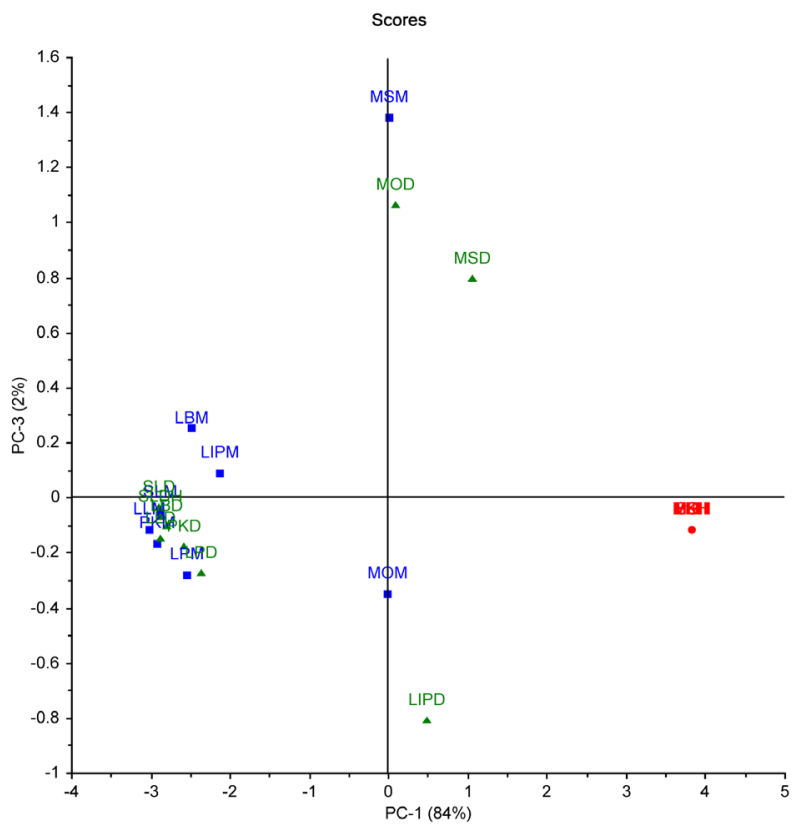

(c)

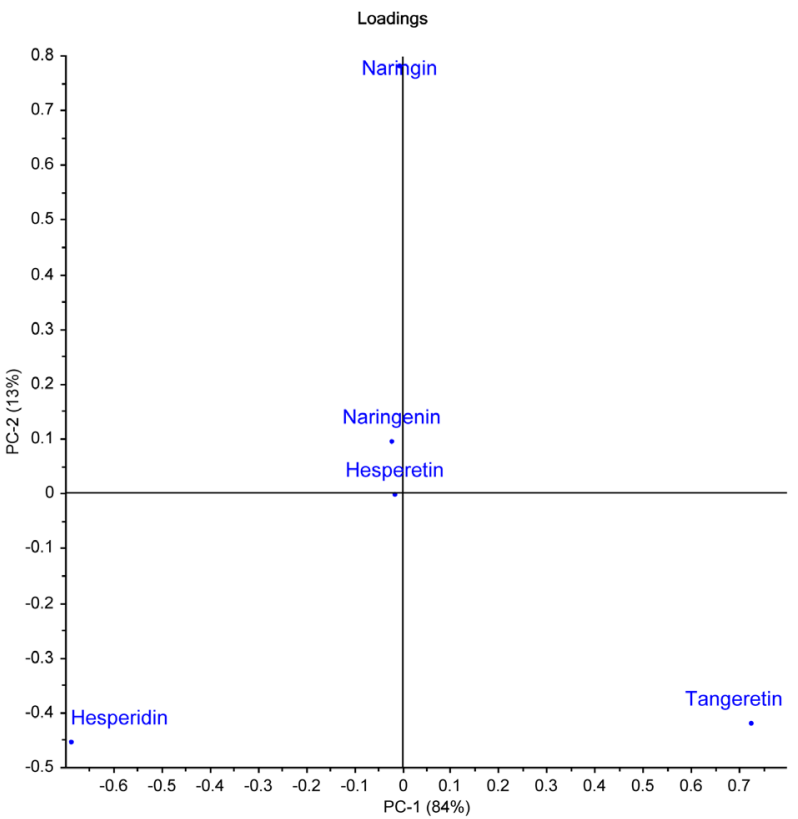

(b)

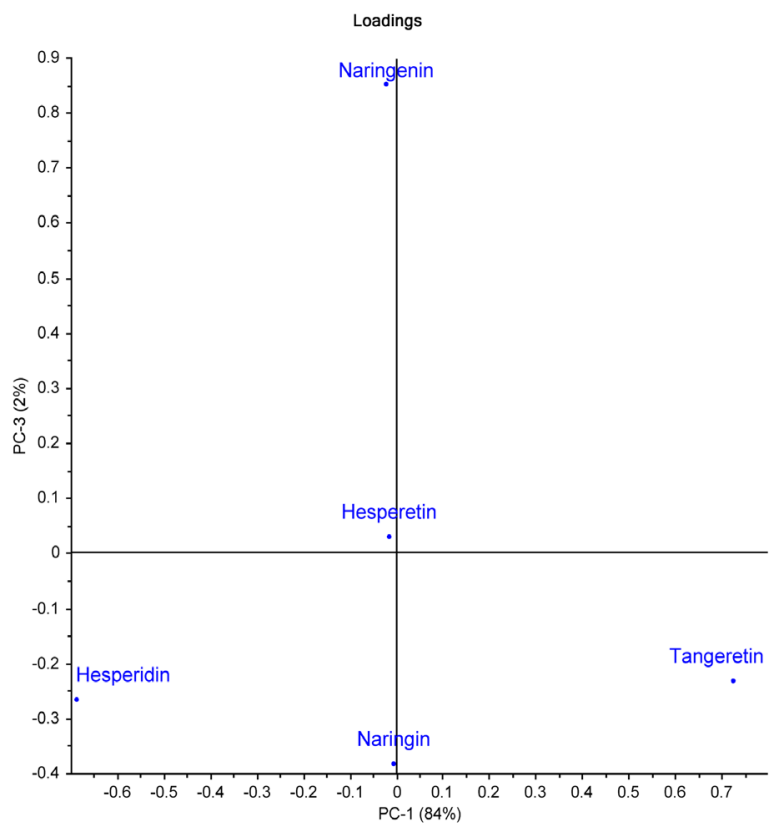

(d)

Figure 3. Principal components (PCA) of orange peels from Brazilian citrus variety. Hexane extracts are in red, methanol extracts are in blue and DMSO extract are represented in green in the scores graphs. The loadings graphs present the flavonoids. (a) Scores of the PC1 vs PC2; (b) loadings of the PC1 vs PC2; (c) scores of the PC1 vs PC3 (d) loadings of the PC1 vs PC3. For abbreviations see Table 1 . 
and higher levels of hesperidin are observed in one of the other groups. The presence and the quantity of naringenin, hesperetin, hesperidin and naringin in the methanol and DMSO extracts, have clustered these samples into two groups. The hierarchical clustering analysis (HCA), using Ward's method, clustered the samples in two groups with a relative distance lower than 5.5 (Figure 4), one belonging to the hexane extract and the other one included the other two extracting solvents. The relative distance is the parameter that determines how similar the samples are, and low values indicate more similarity as it can be observed in samples extracted with methanol and DMSO. Among the ten orange varieties analyzed, it was possible to treat six of them with two different solvents (Table 1), DMSO and methanol. When DMSO was used, the main flavonone extracted was hesperidin in orange peels of bahia (LBD), lima (LLD), seleta (SLD) and ponkan (PKD). The extraction with methanol yielded higher amounts of hesperidin and hesperetin in lima-of-persian peels (LIPM) and thus it was the most efficient solvent for the extraction of these substances. Naringin and tangeretin, on the other hand, were only observed in the DMSO extracts, revealing a selective separation with these solvents (Table 1).

The extraction of hesperetin in bahia (LBM) and lima-of-persian (LIPM) oranges, was only observed in methanol, which supports the statement that methanol is the best solvent to extract hesperidin aglycones, when compared to DMSO and hexane.

The amount of naringenin found in all the orange peels studied was very low, only being observed in the extraction with DMSO. This solvent was also more efficient than methanol in the extraction of tangeretin, however, hexane was the most efficient and selective solvent in the extraction of tangeretin and other polymetoxylated flavanones. None of the flavanones were detected in the hexane extract (Figure 2). This study also shows that hexane is a very selective solvent to extract polymethoxy flavones.

An attempt to increase the flavonones extraction was made using DMSO, after

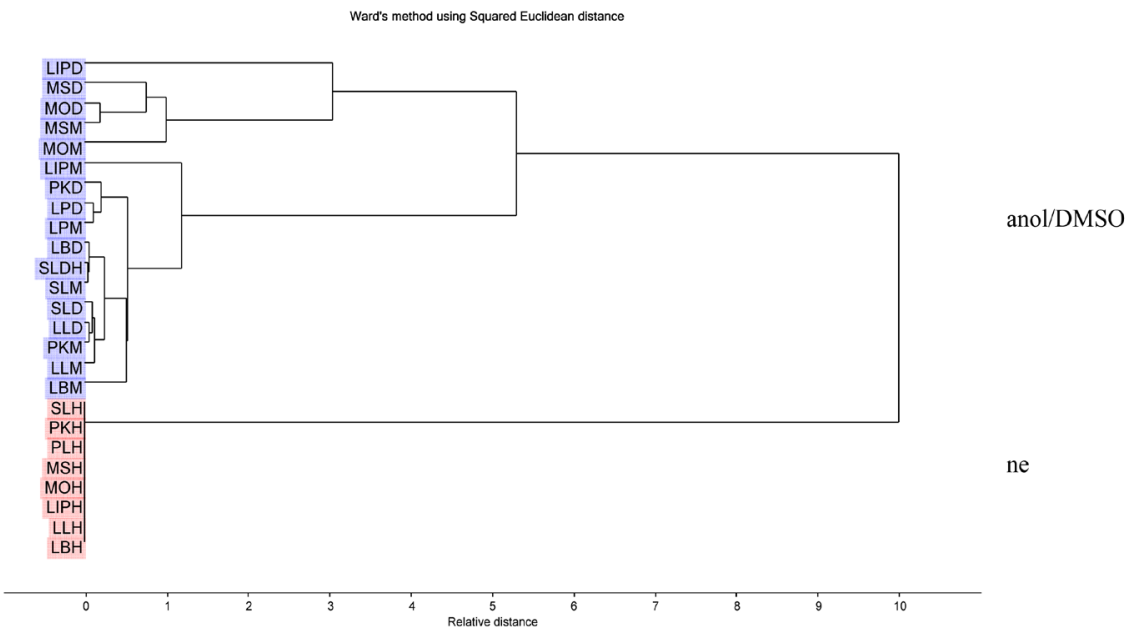

Figure 4. HCA separating the extraction methods for the orange peels. For abbreviations see Table 1. 
extracting seleta peels with hexane obtaining the following concentrations (in $\left.\mathrm{mg} \cdot \mathrm{g}^{-1}\right)$ : naringin from $0.792 \pm 0.002$ to $2.301 \pm 0.077$, hesperidin from $39.388 \pm$ 0.119 to $47.339 \pm 1.128$, naringenin from $2.074 \pm 0.006$ to $2.318 \pm 0.023$ (small change). This study shows that this consecutive extraction was more efficient in the extraction of naringin, hesperidin and naringenin, than when using DMSO alone (Table 1).

This selective extraction of flavonoids is a step forward to separate glycosides flavanones (hesperidin and naringin) from their aglycones (hesperetin and narigenin) and polymethoxylated flavones (tangeretin) (Figure 3 ).

The amount of flavanones and polymethoxyflavones found in orange peels was always higher than those found in their corresponding juices according to the literature. That is the case of the pera variety (Citrus sinensis Osbeck) whose concentration of hesperidin found in the orange juice was $0.269 \mathrm{mg} \cdot \mathrm{g}^{-1}$ [28] which is lower than the amount found in the respective peel that was $8.61 \mathrm{mg} \cdot \mathrm{g}^{-1}$ (Table 1). The bahia variety orange juice presented $0.427 \mathrm{mg}^{-1}{ }^{-1}$ of this substance [28] while the concentration in the orange peels was $41.17 \mathrm{mg} \cdot \mathrm{g}^{-1}$ (LBD, Table 1). The same situation was observed in the lima variety juice which presented $0.223 \mathrm{mg} \cdot \mathrm{g}^{-1}$ of hesperidin and its peel contained $28.30 \mathrm{mg} \cdot \mathrm{g}^{-1}$ (LLD, Table 1). The hesperidin content of the orange juice of the Citrus sinensis Osbeck variety, was similar to that reported in the literature, however the amount of naringin and naringenin was much lower [29]. Similar behavior was observed in other citrus fruit juices from industries all over the world [30].

Molina-Calle et al. [21] reported that the most abundant glycoside flavanones in citrus peels from Spain were naringin, hesperidin and neohesperidin. M'hiri et al. [31] used different operating conditions, such as ultrasound, microwave, supercritical $\mathrm{CO}_{2}$ and high pressure for the flavonoid extraction from oranges (Citrus sinensis) of the Maltese variety. They found that the best condition to extract hesperidin was ultrassonic extration at $125 \mathrm{~W}\left(8.362 \pm 0.296 \mathrm{mg} \cdot \mathrm{g}^{-1}\right)$ and microwave, $200 \mathrm{~W}\left(9.289 \pm 0.007 \mathrm{mg} \cdot \mathrm{g}^{-1}\right)$. The most abundant flavonoids were hesperidin and neohesperidin.

It was reported that capillary electrophoresis (CE) coupled to mass spectrometry (MS) is a good technique to identify and quantify flavonoids in bitter and sweet orange peel samples. The authors found $5.1 \pm 0.2$ and $7.9 \pm 0.7 \mathrm{mg} \cdot \mathrm{g}^{-1}$ of naringin and neohesperidin in bitter orange peel and $26.9 \pm 2.1$ and $35.2 \pm 3.6$ $\mathrm{mg} \cdot \mathrm{g}^{-1}$ of narirutin and hesperidin in sweet orange peel, respectively. In this study the amounts found were between $0.47 \pm 0.01 \mathrm{mg} \cdot \mathrm{g}^{-1}$ (PKM) to $2.98 \pm 0.02$ $\mathrm{mg} \cdot \mathrm{g}^{-1}(\mathrm{LBM})$ of naringin and between $2.10 \pm 0.29 \mathrm{mg} / \mathrm{g}$ (MOD) to $41.17 \pm 0.08$ $\mathrm{mg} \cdot \mathrm{g}^{-1}(\mathrm{LBD})$ of hesperidin, showing a similar amount of the latter as reported in the literature [32] [33].

Liu et al. [23] analyzed the dried ripe pericarp of Citrus reticulata Blanco (the mandarin orange) collected in different parts of China and found contents of naringin between $0.556 \pm 0.009 \mathrm{mg} \cdot \mathrm{g}^{-1}$ and $4.202 \pm 0.040 \mathrm{mg} \cdot \mathrm{g}^{-1}$, amounts of hesperidin from $50.137 \pm 0.301 \mathrm{mg} \cdot \mathrm{g}^{-1}$ to $100.525 \pm 1.398 \mathrm{mg} \cdot \mathrm{g}^{-1}$ and tangeretin from $0.562 \pm 0.003$ to $11.548 \pm 0.093 \mathrm{mg} \cdot \mathrm{g}^{-1}$. Our results are in the same concen- 
tration range of those described by these authors.

Chen et al. [34] reported that the most abundant flavonoid in oranges peels from different places such as China, Canada, and the United States, was hesperidin, as it was observed in the current study. Orange peels showed both antioxidant and anti-inflammatory activities. The presence of hesperidin as a major component in Citrus peels was confirmed by Guccione et al. [35] using HPLCDAD and HPLC-MS techniques.

\subsection{Extraction of Orange Peels only with DMSO}

Orange peels from other citrus species were extracted only with DMSO: cravo (Citrus reticulata Blanco) (LCRD), kinkan (Fortunella margarita) (LRD) [36] and pomelo (Citrus paradisi Macfayden) (POD). The amount of naringin was $\left(\mathrm{mg} \cdot \mathrm{g}^{-1}\right): 1.892 \pm 0.015$ (LCRD), $5.978 \pm 0.580$ (LRD) and $3.980 \pm 0.107$ (POD). Hesperidin and naringenin were found only in LCRD, in amounts of $37.076 \pm$ $0.237 \mathrm{mg} \cdot \mathrm{g}^{-1}$ and $6.762 \pm 0.805 \mathrm{mg} \cdot \mathrm{g}^{-1}$, respectively. Tangeretin was identified and quantified in all samples (in $\mathrm{mg}^{-1} \mathrm{~g}^{-1}$ ), $0.730 \pm 0.203$ (LCRD), $0.168 \pm 0.017$ (LRD) and $0.120 \pm 0.002$. Cravo peels extracted with DMSO (LCRD) showed the highest content of flavonoids (Figure 5).

\subsection{Flavonoids in Industrial Orange Juice Processing Wastes}

In the orange juice production industry, the process to obtain final products from available raw materials, involves a large amount of wastes. Several steps are performed and beyond juice, everything is used with a commercial purpose.

Industrial orange juice processing wastes were extracted in DMSO. In this study, naringin, hesperidin and tangeretin, and flavonoids found in different amounts at each stage of the process were quantified. Naringenin and quercetin were not present at any of the steps (considering a detection limit of $0.003 \mathrm{mg} / \mathrm{g}$ ) and hesperetin was only found in the CORE. The portion used in animal feed (BRD) was rich in hesperidin (greater amount), naringin and tangeretin (Table 2).

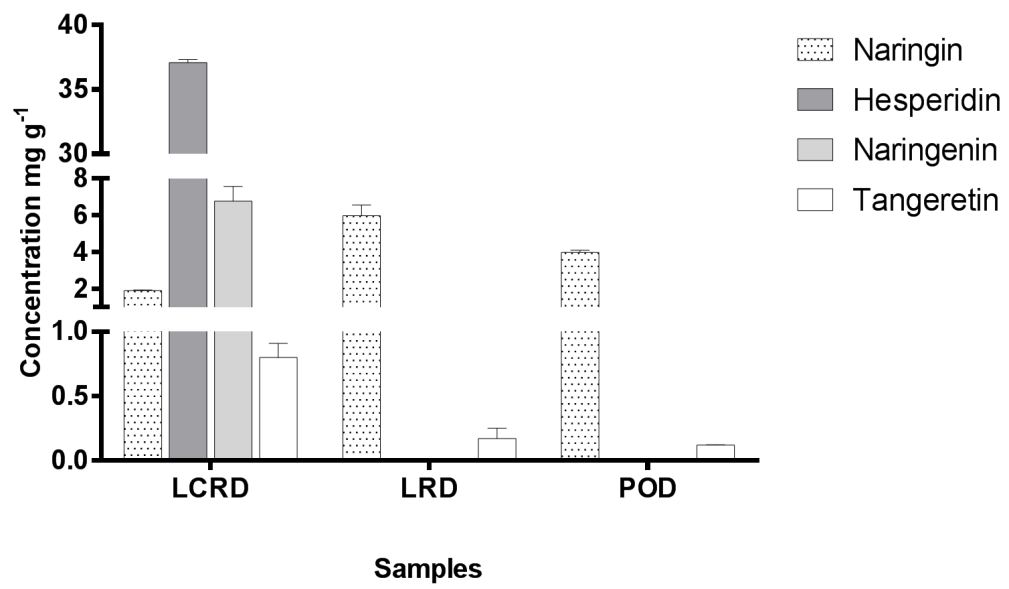

Figure 5. Concentration of flavonoids $\left(\mathrm{mg} \cdot \mathrm{g}^{-1}\right)$ found in orange peels extracted only with DMSO. LCRD is cravo, LRD is kinkan and POD is pomelo. 
Table 2. Flavonoids in wastes of orange juice (expressed in mg of each flavonoid per gram of wastes from orange juice).

\begin{tabular}{cccccc}
\hline \multicolumn{6}{c}{ Flavonoids $^{* *}$} \\
\hline Material $^{*}$ & Naringin & Hesperidin & Hesperetin & Naringenin & Tangeretin \\
\hline BCGD & $1.414 \pm 0.004$ & $22.631 \pm 0.008$ & $0.000 \pm 0.000$ & $0.000 \pm 0.000$ & $0.056 \pm 0.001$ \\
BCD & $3.197 \pm 0.009^{\mathrm{A}}$ & $42.728 \pm 0.075^{\mathrm{C}}$ & $0.000 \pm 0.000$ & $0.000 \pm 0.000$ & $0.136 \pm 0.001^{\mathrm{E}}$ \\
BRD & $5.072 \pm 0.023^{\mathrm{A}}$ & $44.236 \pm 0.016^{\mathrm{C}}$ & $0.000 \pm 0.000$ & $0.000 \pm 0.000$ & $1.930 \pm 0.002^{\mathrm{EF}}$ \\
PUD & $0.956 \pm 0.011^{\mathrm{B}}$ & $11.496 \pm 0.007^{\mathrm{D}}$ & $0.000 \pm 0.000$ & $0.000 \pm 0.000$ & $0.000 \pm 0.000$ \\
CRD & $5.807 \pm 0.040^{\mathrm{A}}$ & $34.206 \pm 0.013^{\mathrm{C}}$ & $2.149 \pm 0.004$ & $0.000 \pm 0.000$ & $0.000 \pm 0.000$ \\
\hline
\end{tabular}

${ }^{*}$ Results in triplicates $( \pm \mathrm{SD})$. Legend: BCGD, "Bagacilio"; BCD, Bagasse; BRD, Bagasse for animal food; PUD, Pulp WEUE and CRD, CORE. Means within a column of Narigin sharing the letter A are significantly increased $(p>0.05)$ by One-Way ANOVA compared to BCGD, B are significantly reduced $(p>0.05)$ by One-Way ANOVA compared to BCGD. Means within a column of Hesperidin sharing the letter C are significantly increased $(p>0.05)$ by One-Way ANOVA compared to BCGD, D are significantly reduced ( $p>$ 0.05 ) by One-Way ANOVA compared to BCGD. Means within a column of Tangeretin sharing the letter E are significantly increased $(\mathrm{p}>0.05$ ) by One-Way ANOVA compared to BCGD, F are significantly increased $(\mathrm{p}>0.05)$ by One-Way ANOVA compared to BCD.

The finding that the concentration of these important compounds is higher in these fruit peels than in their juice clearly indicates that orange peels are an important industry source [37] [38]. The demonstrated possibilities of simple and selective extraction of these compounds entitles them as an alternative for industrial production.

\section{Conclusion}

The extraction of flavanones and polymethoxylated flavones from orange peels of different citrus species, using different solvent systems, allowed the identification and quantification of the flavonoid composition in each Brazilian citrus variety and the selection of the best solvent for the extraction of each specific class of flavonoids. It was determined that hexane is a selective solvent to extract polymethoxy flavones like tangeretin. The consecutive extraction using hexane and then DMSO was more efficient in the extraction of naringin, hesperidin and naringenin, than when using DMSO alone. The extracting procedures used in this work showed that these compounds are more abundant in the fruit peels than in their juices, revealing their great industrial potential. Industrial orange juice processing wastes, in all the processing steps, are also rich in hesperdin, with similar (or proportional) amounts as the ones found in the peels, and thus they are a promising source of this flavonoid. The combination of techniques such as HPLC-DAD and PCA is a powerful tool to evaluate clusters and confirm, in this case, what solvent is most effective extracting flavonoids in orange peels.

\section{Acknowledgements}

We are grateful to Lincoln A.Kurihara for your technical support and for Citrovita Agroindustrial Ltda. for providing the industry processing juice waste samples. 


\section{References}

[1] Hertog, M.G.L., Feskens, E.J.M., Kromhout, D., Hollman, P.C.H. and Katan, M.B. (1993) Dietary Antioxidant Flavonoids and Risk of Coronary Heart Disease: The Zutphen Elderly Study. The Lancet, 342, 1007-1011. https://doi.org/10.1016/0140-6736(93)92876-U

[2] Benavente-García, O., Castillo, J., Marin, F.R., Ortuño, A. and Del Río, J.A. (1997) Uses and Properties of Citrus Flavonoids. Journal of Agricultural and Food Chemistry, 45, 4505-4515. https://doi.org/10.1021/jf970373s

[3] Yao, L.H., Jiang, Y.M., Shi, J., Tomás-Barberán, F.A., Datta, N., Singanusong, R. and Chen, S.S. (2004) Flavonoids in Food and Their Health Benefits. Plant Foods for Human Nutrition, 59, 113-122. https://doi.org/10.1007/s11130-004-0049-7

[4] Benavente-García, O. and Castillo, J. (2008) Update on Uses and Properties of Citrus Flavonoids: New Findings in Anticancer, Cardiovascular, and Anti-Inflammatory Activity. Journal of Agricultural and Food Chemistry, 56, 6185-6205. https://doi.org/10.1021/jf8006568

[5] Manthey, J.A., Guthrie, N. and Grohmann, K. (2001) Biological Properties of Citrus Flavonoids Pertaining to Cancer and Inflammation. Current Medicinal Chemistry, 8, 135-153. https://doi.org/10.2174/0929867013373723

[6] Tripoli, E., Guardia, M.L., Giammanco, S., Majo, D.D. and Giammanco, M. (2007) Citrus Flavonoids: Molecular Structure, Biological Activity and Nutritional Properties: A Review. Food Chemistry, 104, 466-479.

[7] Cavia-Saiz, M., Busto, M.D., Pilar-Izquierdo, M.C., Ortega, N., Perez-Mateos, M. and Muñiz, P. (2010) Antioxidant Properties, Radical Scavenging Activity and Biomolecule Protection Capacity of Flavonoid Naringenin and Its Glycoside Naringin: A Comparative Study. Journal of Science of Food and Agriculture, 90, 12381244. https://doi.org/10.1002/jsfa.3959

[8] Madeira Jr., J.V. and Macedo, G.A. (2015) Simultaneous Extraction and Biotransformation Process to Obtain High Bioactivity Phenolic Compounds from Brazilian Citrus Residues. Biotechnology Progress, 31, 1273-1279. https://doi.org/10.1002/btpr.2126

[9] Sergent, T., Vanderstraeten, J., Winand, J., Beguin, P. and Schneider, Y.J. (2012) Phenolic Compounds and Plant Extracts as Potential Natural Anti-Obesity Substances. Food Chemistry, 135, 68-73.

[10] Arabbi, P.R., Genovese, M.I. and Lajolo, F.M. (2004) Flavonoids in Vegetable Foods Commonly Consumed in Brazil and Estimated Ingestion by the Brazilian Population. Journal of Agricultural and Food Chemistry, 52, 1124-1131. https://doi.org/10.1021/jf0499525

[11] Hernández-Carranza, P., Ávila-Sosa, R., Guerrero-Beltrán, J.A., Navarro-Cruz, A.R., Corona-Jiménez, E. and Ochoa-Velasco, C.E. (2016) Optimization of Antioxidant Compounds Extraction from Fruit By-Products: Apple Pomace, Orange and Banana Peel. Journal of Food Processing and Preservation, 40, 103-115. https://doi.org/10.1111/jfpp.12588

[12] Ghasemi, K., Ghasemi, Y. and Ebrahimzadeh, M.A. (2009) Antioxidant Activity, Phenol and Flavonoid Contents of 13 Citrus Species Peels and Tissues. Pakistan Journal of Pharmaceutical Sciences, 22, 277-281.

[13] Bocco, A., Cuvelier, M.E., Richard, H. and Berset, C. (1998) Antioxidant Activity and Phenolic Composition of Citrus Peel and Seed Extracts. Journal of Agricultural and Food Chemistry, 46, 2123-2129. https://doi.org/10.1021/jf9709562

[14] Anagnostopoulou, M.A., Kefalas, P., Papageorgiou, V.P., Assimopoulou, A.N. and 
Boskou, D. (2006) Radical Scavenging Activity of Various Extracts and Fractions of Sweet Orange Peel (Citrus sinensis). Food Chemistry, 94, 19-25.

[15] Hirano, T., Abe, K., Gotoh, M. and Oka, K. (1995) Citrus Flavone Tangeretin Inhibits Leukaemic HL-60 Cell Growth Partially through Induction of Apoptosis with Less Cytotoxicity on Normal Lymphocytes. British Journal of Cancer, 72, 1380 1388. https://doi.org/10.1038/bjc.1995.518

[16] Itoigawa, M., Takeya, K. and Furukawa, H. (1994) Cardiotonic Flavonoids from Citrus Plants (Rutaceae). Biological and Pharmaceutical Bulletin, 17, 1519-1521. https://doi.org/10.1248/bpb.17.1519

[17] Ehler, S.A. (2011) Citrus and Its Benefits. Journal of Botany, 5, 201-207.

[18] So, F.V., Guthrie, N., Chambers, A.F., Moussa, M. and Carroll, K.K. (1996) Inhibition of Human Breast Cancer Cell Proliferation and Delay of Mammary Tumorigenesis by Flavonoids and Citrus Juices. Nutrition and Cancer, 26, 167-181. https://doi.org/10.1080/01635589609514473

[19] Ramos, S. (2007) Effects of Dietary Flavonoids on Apoptotic Pathways Related to Cancer Chemoprevention. Journal of Nutritional Biochemistry, 18, 427-442. https://doi.org/10.1016/j.jnutbio.2006.11.004

[20] Meiyanto, E., Hermawan, A. and Anindyajati, A. (2012) Natural Products for Cancer-Targeted Therapy: Citrus Flavonoids as Potent Chemopreventive Agents. Asian Pacific Journal of Cancer Prevention, 13, 427-436. https://doi.org/10.7314/APJCP.2012.13.2.427

[21] Molina-Calle, M., Priego-Capote, F. and Luque de Castro, M.D. (2015) Development and Application of a Quantitative Method for Determination of Flavonoids in Orange Peel: Influence of Sample Pretreatment on Composition. Talanta, 144, 349 355.

[22] Nijveldt, R.J., van Nood, E., van Hoorn, D.E., Boelens, P.G., van Norren, K. and van Leeuwen, P.A. (2001) Flavonoids: A Review of Probable Mechanisms of Action and Potential Applications. American Journal of Clinical Nutrition, 74, 418-425.

[23] Liu, E.H., Zhao, P., Duan, L., Zheng, G.D., Guo, L., Yang, H. and Li, P. (2013) Simultaneous Determination of Six Bioactive Flavonoids in Citri reticulatae Pericarpium by Rapid Resolution Liquid Chromatography Coupled with Triple Quadrupole Electrospray Tandem Mass Spectrometry. Food Chemistry, 141, 3977-3983.

[24] Abad-García, B., Garmón-Lobato, S., Berrueta, L.A., Gallo, B. and Vicente, F. (2012) On Line Characterization of 58 Phenolic Compounds in Citrus Fruit Juices from Spanish Cultivars by High-Performance Liquid Chromatography with Photodiode-Array Detection Coupled to Electrospray Ionization Triple Quadrupole Mass Spectrometry. Talanta, 99, 213-224.

[25] Ćirić, A., Prosen, H., Jelikić-Stankov, M. and Durđević, P. (2012) Evaluation of Matrix Effect in Determination of Some Bioflavonoids in Food Samples by LC-MS/MS method. Talanta, 99, 780-790.

[26] Da Rocha, A.S. (2006) Características bioquímicas em cascas, folhas e talos de vegetais pós-colheita em sistema de produção convencional e orgânico. Dissertation, Unesp, Botucatu, SP, Brasil.

[27] Omoba, O.S., Obafaye, R.O., Salawu, S.O., Boligon, A.A. and Athayde, M.L. (2015) HPLC-DAD Phenolic Characterization and Antioxidant Activities of Ripe and Unripe Sweet Orange Peels. Antioxidants, 4, 498-512.

https://doi.org/10.3390/antiox4030498

[28] Pupin, A.M., Dennis, M.J. and Toledo, M.C.F. (1998) Flavone Glycosides in Brazilian Orange Juice. Food Chemistry, 61, 275-280. 
[29] Cerqueira, L.C.R., David, J.M., Borges, R.S.Q., Ferreira, S.L.C., David, J.P., Reis, P.S., and Bruns, R.E. (2014) Determination of Flavanones in Orange Juices Obtained from Different Sources by HPLC/DAD. Journal of Analytical Methods in Chemistry, 14, 13-18.

[30] Mouly, P., Gaydou, E.M. and Auffray, A. (1998) Simultaneous Separation of Flavanone Glycosides and Polymethoxylated Flavones in Citrus Juices Using Liquid Chromatography. Journal of Chromatography A, 800, 171-179.

[31] M'hiri, N., Ioannou, I., Mihoubi Boudhrioua, N. and Ghoul, M. (2015) Effect of Different Operating Conditions on the Extraction of Phenolic Compounds in Orange Peel. Food and Bioproducts Processing, 96, 161-170. https://doi.org/10.1016/j.fbp.2015.07.010

[32] Sawalha, S.M.S., Arráez-Román, D., Segura-Carretero, A. and Fernández-Gutiérrez, A. (2009) Quantification of Main Phenolic Compounds in Sweet and Bitter Orange Peel Using CE-MS/MS. Food Chemistry, 116, 567-574.

[33] Massenti, R., Lo Bianco, R., Sandhu, A.K., Gu, L. and Sims, C. (2016) Huanglongbing Modifies Quality Components and Flavonoid Content of "Valencia" Oranges. Journal of Science and Food Agriculture, 96, 73-78. https://doi.org/10.1002/jsfa.7061

[34] Chen, X.M., Tait, A.R. and Kitts, D.D. (2017) Flavonoid Composition of Orange Peel and Its Association with Antioxidante and Anti-Inflammatory Activities. Food Chemistry, 218, 15-21.

[35] Guccione, C., Bergonzi, M.C., Piazzini, V. and Bilia, A.R. (2016) A Simple and Rapid HPLC-PDA MS Method for the Profiling of Citrus Peels and Traditional Italian Liquors. Planta Medica, 82, 1039-1045. https://doi.org/10.1055/s-0042-108735

[36] Diniz, A.B. and Oliveira, D.R. (2015) Composição química da laranja kinkan e de frutas cítricas. Demetra, 10, 835-844.

[37] Shahwar, D., Raza, M.A. and Atta, U.R. (2013) Identification of Flavonoids with Trypsin Inhibitory Activity Extracted from Orange Peel and Green Tea Leaves. Journal of Science of Foods and Agriculture, 93, 1420-1426. https://doi.org/10.1002/jsfa.5910

[38] Munhoz, J.R. and Morabito, R. (2010) Otimização no planejamento agregado de produção em indústrias de processamento de suco concentrado congelado de laranja. Gestão \& Produção, 17, 465-481. https://doi.org/10.1590/S0104-530X2010000300003 
Submit or recommend next manuscript to SCIRP and we will provide best service for you:

Accepting pre-submission inquiries through Email, Facebook, LinkedIn, Twitter, etc. A wide selection of journals (inclusive of 9 subjects, more than 200 journals)

Providing 24-hour high-quality service

User-friendly online submission system

Fair and swift peer-review system

Efficient typesetting and proofreading procedure

Display of the result of downloads and visits, as well as the number of cited articles Maximum dissemination of your research work

Submit your manuscript at: http://papersubmission.scirp.org/

Or contact as@scirp.org 